\title{
REDES DE RELACIONAMENTO DOS EMPREENDEDORES E A INOVAÇÃO DE PRODUTOS: UMA ANÁLISE COM PEQUENAS EMPRESAS DO PROGRAMA ALI
}

Gustavo Passos Fortes ${ }^{1}$

Rivanda Meira Teixeira ${ }^{2}$

\footnotetext{
${ }^{1}$ Universidade Federal do Sul e Sudeste do Pará

${ }^{2}$ Universidade Federal do Paraná - Campus Palotina
} 


\section{REDES DE RELACIONAMENTO DOS EMPREENDEDORES E A INOVAÇÃO DE PRODUTOS: UMA ANÁLISE COM PEQUENAS EMPRESAS DO PROGRAMA ALI}

Resumo: Na pequena empresa, o empreendedor deve articular sua rede social de diferentes níveis e tipos, para que seja possível conceber a inovação. Porém, apesar da importância das redes sociais empreendedoras para a construção da inovação, o tema ainda é pouco explorado O objetivo deste estudo é verificar como as redes sociais dos empreendedores favorecem a implementação de inovações de produto de empresas participantes do Programa Agentes Locais de Inovação-ALI. Foi utilizado o método de estudo de casos múltiplos, que permite obter uma maior compreensão do contexto do fenômeno estudado. Foram selecionados três casos, coletadas evidências de entrevistas semiestruturadas. Os resultados apontam que as inovações implementadas pelas empresas analisadas têm semelhanças devido à padronização da intervenção do programa ALI e percebeu-se ainda uma tendência em inovar utilizando novas tecnologias, principalmente com subsídios do SEBRAETec.

Palavras-chave: Empreendedorismo. Inovação. Pequenas Empresas. Network. 


\section{Introdução}

Estudos clássicos indicam que as redes sociais empreendedoras são relacionadas de forma positiva com o desempenho e sobrevivência de uma pequena empresa (OSTGAARD; BIRLEY, 1994; BAUMOL, 2002, 1998; DRUKER, 2002). Também apontam a importância da inovação tanto para a sobrevivência das pequenas empresas quanto para o desenvolvimento econômico e social (JULIEN, 2010; DRUKER, 2002). Apesar da constatação da importância das redes de relacionamento para o empreendedorismo e para a inovação, esse processo ainda é pouco explorado (HUGGINS; THOMPSON, 2015).

Os trabalhos de Schumpeter (1991) inserem o empreendedor no cerne da análise, colocando-o como o centro do processo de mudanças e transformações econômicas através da inovação. Assim, os campos de estudo do empreendedorismo e da pequena empresa estão diretamente relacionados, cabendo ressalta que o sucesso de uma pequena empresa depende das decisões e o comportamento do empreendedor, das inovações e consequentemente das redes sociais empreendedoras (PARTANEN; CHETTY; RAJALA, 2014; VALLE, 2015).

A pequena empresa encontra diversas dificuldades para a geração e implementação de inovações, que prejudicam seriamente a competitividade e sobrevivência dessas organizações (CAMPOS; CAMPOS, 2013; VRANDE et al, 2009). O desenvolvimento de inovações no contexto da pequena empresa auxilia o empreendedor na exploração das mudanças, enxergando como oportunidades para a diferenciação de um negócio (PAREDES et al, 2015). A sobrevivência e competitividade da pequena empresa estão diretamente relacionadas à capacidade do empreendedor de buscar e explorar oportunidades de inovação (UKKO; SAUNILA, 2013; DRUCKER, 2002).

Considerando que a inovação é um fator determinante para a sobrevivência da pequena empresa, o empreendedor deve contar com os recursos obtidos em seus relacionamentos sociais para que seja possível adoção de ações inovadoras (VALLE; GUIMARÃES, 2014). Birley (1985) destaca que o empreendedor não depende apenas de recursos físicos e financeiros para a condução de seu negócio, mas também de conselhos, informações, opiniões, confiança e contatos de negócios. Da mesma forma, na inovação na pequena empresa, o empreendedor deve articular sua rede de contatos de diferentes níveis e tipos, para que seja possível conceber a inovação (PARTANEN, CHETTY e RAJALA, 2014).

Assim, explorar os tipos de redes sociais que são mobilizadas pelos empreendedores no decorrer da ação de inovação e identificar os recursos acessados por meio dos relacionamentos são elementos considerados importantes para os empreendedores (BORGES, 2011; VALE; WILKINSON; AMÂNCIO, 2008; PARTANEN; CHETTY; RAJALA, 2014). É importante no sentido de compreender os recursos que os laços fortes ou fracos podem disponibilizar para condução da ação inovadora (BIRLEY, 1985, GRANOVETTER, 2007).

O presente estudo tem o objetivo de verificar como as redes sociais dos empreendedores favorecem a implementação de inovações em produto ou serviços de empresas de sucesso participantes do Programa Agentes Locais de Inovação - ALI. Descrevendo as ações de inovação em produto adotadas pelos empreendedores estudados, caracterizando os tipos de redes sociais utilizadas e os recursos acessados em cada uma delas.

A contribuição teórica deste estudo se dá ao analisar a utilização das redes sociais empreendedoras para favorecer as ações de inovação nas empresas de pequeno porte casos de

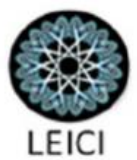


sucesso do Programa ALI. Assim, pretende-se destacar a compreensão das contribuições práticas do desenvolvimento da rede social empreendedora para ter acesso aos recursos necessários para a implantação de ações de inovação na pequena empresa.

\section{Referencial Teórico}

\subsection{Inovação na Micro e Pequena Empresa}

No Brasil, normalmente usa-se os critérios do SEBRAE (2014) que considera MPEs as empresas de pequeno porte com faturamento bruto anual inferior à $\mathrm{R} \$ 3,6$ milhões. De acordo com esse critério, as microempresas são enquadradas de acordo com seu faturamento, que pode chegar até $\mathrm{R} \$ 360$ mil, enquanto as pequenas empresas possuem um limite de faturamento que pode variar, acima de $\mathrm{R} \$ 360$ mil até $\mathrm{R} \$ 3,6$ milhões.

Assim como no campo de estudo do empreendedorismo e pequenas empresas, o conceito de inovação no âmbito empresarial encontra diversas explicações que não são totalmente excludentes entre si (RESENDE JUNIOR; GUIMARÃES, 2012; PAREDES et al, 2015). Na verdade, tais explicações são complementares, tal como afirmam Freeman e Soete (2009), destacando que essa diversidade de conceitos evolui o campo, possibilitando a abrangência de diferentes aspectos da inovação, não se limitando apenas a indicadores tecnológicos de Pesquisa e Desenvolvimento (P\&D).

Buscando uma definição comum para o tema, o Manual de Oslo, que é utilizado como referência para inovação em diversos países, define inovação como a "implementação de um produto (bem ou serviço) novo ou significativamente melhorado, ou um processo, ou um novo método de marketing, ou um novo método organizacional nas práticas de negócios, na organização do local de trabalho ou nas relações externas" (OCDE \& FINEP, 2005, p. 55).

Um dos principais aspectos abordados nos estudos da inovação se refere às tipologias (BAREGHEH, ROWLEY E SAMBROOK, 2009). Nesse sentido, a inovação de produto é a introdução de um produto/serviço novo, ou aperfeiçoado, que apresente alterações significativas em suas características (OCDE; FINEP, 2005; TIDD, BESSANT E PAVITT, 2008; RAMANI; MUKHERJEE, 2014).

A inovação assume papel crucial para a sobrevivência das pequenas empresas (MELLO; MACHADO; JESUS, 2010; MEISSNER; KOTSEMIR, 2016). Nesse sentindo, Schumpeter (1998) destacou os efeitos da inovação no desenvolvimento e crescimento econômico, ressaltando a importância do empreendedor e, consequentemente da pequena empresa na construção de inovações. Seguindo nessa mesma linha de argumentação, Druker (2002) reforça a relevância da inovação das pequenas empresas para a construção de riquezas e desenvolvimento econômico.

As inovações na pequena empresa são, em geral, classificadas como incrementais e dependem quase que exclusivamente das características particulares das MPEs (BOTELHO; CARRIJO; KAMASAKI, 2007; MALDONADO; DIAS; VARVAKIS, 2009). Para os autores, a inovação é resultado da criatividade vivenciada pelos líderes das empresas na gestão de todos os seus processos. Portanto, a inovação na pequena empresa deve ser analisada sob uma ótica que considere suas particularidades de atuação de cada pequena empresa.

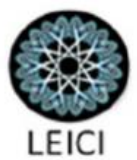


Tavares, Ferreira e Lima (2009) enfatizam a importância do papel do proprietário/empreendedor e sua influencia em todo o ambiente organizacional da MPE, ressaltando as dificuldades para a inovação, como por exemplo, a centralidade excessiva e benefícios, como a flexibilidade. Alvim (1997) corrobora essa caracterização da flexibilidade, decorrente da inovação, expondo que a sobrevivência dessas empresas, está cada vez mais condicionada ao processo de aprendizagem, que deve ser permanente e se desenvolver através das atividades de capacitação, assimilação e utilização. Com o processo de aprendizagem é possível desenvolver oportunidades empreendedoras para a pequena empresa que se beneficia da vantagem de reagir mais rapidamente às mudanças externas, aproveitando as oportunidades de inovação (ALVIM, 1997).

Com objetivo de agir na redução da taxa de mortalidade nas MPEs, o SEBRAE desenvolveu uma metodologia para o Programa Agentes Locais de Inovação, buscando o aumento da competitividade das micro e pequenas empresas, por meio da difusão de informações sobre inovação, tecnologia e aplicação de soluções, adaptadas às características de cada negócio, gerando impacto direto na gestão empresarial, na melhoria de produtos e serviços (SILVA NETO; TEIXEIRA, 2011).

\subsection{Redes Sociais Empreendedoras e a Inovação}

Para Granovetter (1985), o criador da chamada Nova Sociologia Econômica, as redes são formadas por dois tipos de laços: 1) laços fracos, constituídos por contatos eventuais e esporádicos; 2) laços fortes, que se caracterizam por contatos intensos e frequentes. Assim, de forma geral, Newbert, Tornikoski e Quigley (2013) afirmam que os empresários devem adquirir recursos a partir de um conjunto cada vez mais diversificado de laços fortes e um número ainda maior de laços fracos.

Fligstein e Dauter (2012, p. 488), afirmam que a sociologia econômica é uma "tentativa de incluir os sociólogos no estudo do mundo econômico, inserindo a teoria social e a maneira como funciona a vida social em geral nas firmas, mercados e indústrias". Em outras palavras analisam a economia pela ótica da sociologia, o que consequentemente tem impactos no campo de estudo da administração.

A tese central da nova sociologia econômica desdobra reflexões sobre o papel das vinculações sociais no mundo econômico, com o conceito de embeddedness (GRANOVETTER, 1985). Tal termo denota que ações e transações econômicas estão enraizadas nos relacionamentos e não é possível analisar tais ações econômicas sem considerar as relações sociais e o contexto social do indivíduo (GRANOVETTER, 1985; VALLE, 2015).

De forma complementar, as redes podem ser classificadas como as relações sociais dinâmicas que são estabelecidas de acordo com a troca de ideias, informações, mercadorias, poder e amizade (ALDRICH; ZIMMER, 1986). Assim, as redes sociais se referem aos objetos, pessoas ou grupos de pessoas (ALDRICH; ZIMMER, 1986) que podem fornecer recursos tais como capital e informação (OSTGAARD; BIRLEY, 1994), bem como apoio para as ideias em áreas nas quais o individuo não possui conhecimento especial (ALDRICH; ZIMMER, 1986; OSTGAARD; BIRLEY, 1994).

As redes pessoais que são caracterizadas pelos contatos e relacionamentos pessoais do empreendedor compostas pelos amigos e familiares auxiliam o empreendedor em

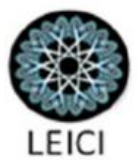


determinados recursos importantes para a abertura da empresa e seu posterior crescimento (DUBINI; ALDRICH, 1991; JENSEN; SCHOTT, 2014). Assim, é natural que o empreendedor recorra e envolva sua rede de contato pessoal nas atividades diárias de uma empresa nascente e à medida que vai desenvolvendo seus processos e se consolidando no mercado, vai necessitando recorrer mais as redes de negócios. (STAM; ARZLANIAN; ELFRING; 2014). Essas redes de negócios são entendidas como uma rede estendida que é, em parte, moldada pela rede pessoal em torno do empresário (JENSEN; SCHOTT, 2014), assim na concepção de Dubini e Aldrich (1991) essa rede é formada por fornecedores, clientes e concorrentes e outros contatos profissionais que fornecem informações e recursos necessários para a empresa.

Naturalmente, o empreendedor é o responsável pelo processo de criação de uma inovação na pequena empresa e sem o indivíduo não há processo inovativo (BRUYAT; JULIAN, 2000). De acordo com Partanen, Chetty e Rajala (2014), as pequenas empresas contam com poucos recursos em termos financeiros, tecnológicos (P\&D), físicos e recursos intangíveis tais como informações de mercado e invenções. Essa realidade faz com que o empreendedor tenha que complementar seus recursos através do envolvimento de diferentes tipos de redes de relacionamento (DUBINI; ALDRICH, 1991; PITTAWAY et al., 2004; PARTANEN, CHETTY e RAJALA, 2014).

A própria dinâmica da pequena empresa substitui a possibilidade de inovações oriundas do ambiente interno por inovações pautadas em conhecimentos externos, de relacionamentos com agentes de fora da organização tais como instituições de pesquisa, órgãos governamentais, fornecedores, clientes e parceiros (HAGE; HOLLINGSWORTH, 2000; PITTAWAY et al., 2004; LEENDERS; DOLFSMA, 2016).

Tais agentes externos constituem a rede de relacionamento do empreendedor e são uma das principais fontes de recursos para a inovação (PITTAWAY et al., 2004; PARTANEN, CHETTY e RAJALA, 2014). De forma similar, vários autores destacam que, no processo de inovação, o empreendedor deve recorrer a relacionamentos com universidades ou institutos de pesquisa (HAGE; HOLLINGSWORTH, 2000; LEENDERS; DOLFSMA, 2016), parceiros do mesmo segmento (ROTHAERMEL; DEEDS, 2006), clientes (DEPROPRIS, 2002) e fornecedores (DEPROPRIS, 2002).

Para a inovação, o empreendedor precisa identificar as oportunidades, posteriormente classificar os recursos necessários, planejar a ação e em seguida partir para a de exploração da oportunidade (RAMANI; MUKHERJEE, 2014). Em cada uma dessas fases, os relacionamentos sociais influenciam de forma diferente o sucesso ou não da inovação (ELFRING; HULSINK, 2007; PARTANEN, CHETTY; RAJALA, 2014). É preciso identificar de forma concreta como cada relacionamento pode contribuir em cada uma dessas fases, verificando os recursos disponibilizados por cada tipo de relacionamento identificado.

\section{Aspectos Metodológicos}

Este estudo se caracteriza como qualitativo, buscando compreender os fenômenos a partir da perspectiva do empreendedor. Tal abordagem favorece a interação do pesquisador com o empreendedor, garantindo maior profundidade dos dados, bem como a exploração de múltiplos fatores envolvidos (CRESWELL, 2009). Pode ser classificado como exploratório que segundo Neuman (1997) tem como principal objetivo explorar temas com poucos estudos

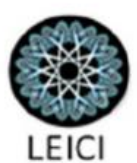


desenvolvidos, como temas novos ou emergentes (NEUMAN, 1997). Também pode ser caracterizado como descritivo, com o objetivo de retratar e descrever as características de uma pessoa, evento ou situação, fazendo comparações e análises comparativas com outros casos e estudos (SAUNDERS; LEWIS; THORNHILL 2007).

O método adotado foi o estudo de casos múltiplos, que para Yin (2010) permite a analise do fenômeno com profundidade. Esse método possibilita obter uma maior compreensão do contexto estudado, assim como seus processos e comparações (SAUNDERS; LEWIS; THORNHILL, 2009). Assim, foi escolhida como unidade de análise o empreendedor e suas redes de relacionamento utilizadas nas ações de inovação durante o atendimento do Programa ALI.

Foram utilizadas as seguintes fontes de evidências neste estudo: entrevista (semiestruturada) e pesquisa documental. Na entrevista semiestruturada o pesquisador conta com a lista de temas e questões a serem abordadas, mas são modificadas no decorrer da entrevista a depender do contexto, possibilitando outras constatações além das previstas (SAUNDERS; LEWIS; THORNHILL, 2009). Na pesquisa documental, o pesquisador busca acessar documentos cedidos pelo entrevistador, outros parceiros e instituições que reforcem as evidencias coletada e possibilitem analises mais aprofundada do caso (SAUNDERS; LEWIS; THORNHILL, 2009).

Para esse estudo foram consideradas seis entrevistas com empreendedores casos de sucesso do Programa ALI que implementaram ações de inovação em produto ou serviços em suas respectivas empresas e também com três agentes locais de inovação que atuaram nas empresas selecionadas. Cada entrevista teve duração média de 1 hora e meia e foi gravada utilizando-se gravador de áudio digital, transcritas e, posteriormente, categorizadas de acordo com os elementos de análise.

A pesquisa documental utilizou-se de relatórios e documentos, tais como relatórios de devolutiva do radar da inovação, planos de ações propostos e executados, termos de adesão e descrição de case de sucesso. A pesquisa documental pretende complementar a análise e entender a dinâmica dos relacionamentos e recursos acessados em cada ação de inovação.

Este estudo utilizou a amostragem teórica que, de acordo com Eisenhardt (1989) permite trabalhar com casos suscetíveis de serem replicados, buscando com isso estender a teoria. O mesmo autor afirma que o número de casos é fixado no alcance da "saturação teórica", que acontece em média entre 4 a 10 casos, ou seja, quando os fenômenos estudados começam a se repetir, sem maiores contribuições (EISENHARDT, 1989).

Os casos foram selecionados em função dos seguintes critérios: (1) empresas de pequeno porte - até 49 funcionários (SEBRAE, 2014); (2) mínimo de 2 anos de atuação; (3) atuação em uma das cadeias produtivas atendidas pelo programa ALI; (4) empresas consideradas casos de sucesso de inovação no Programa ALI.

Como caso de sucesso, foram estabelecidos os seguintes critérios: (1) a empresa participou ativamente do programa ALI por mais de 1 ano e meio; (2) executou no mínimo 6 ações de inovação; (3) obteve melhoria no radar da inovação avaliados em pelo menos 2 momentos distintos e; (4) apresentou uma melhora significativa no grau de inovação medido no diagnostico radar da inovação.

As categorias analíticas do estudo foram baseadas nos objetivos específicos e seus elementos de análise estão detalhados no Quadro 1:

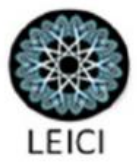


Quadro 1 - Categorias analíticas e elementos de análise

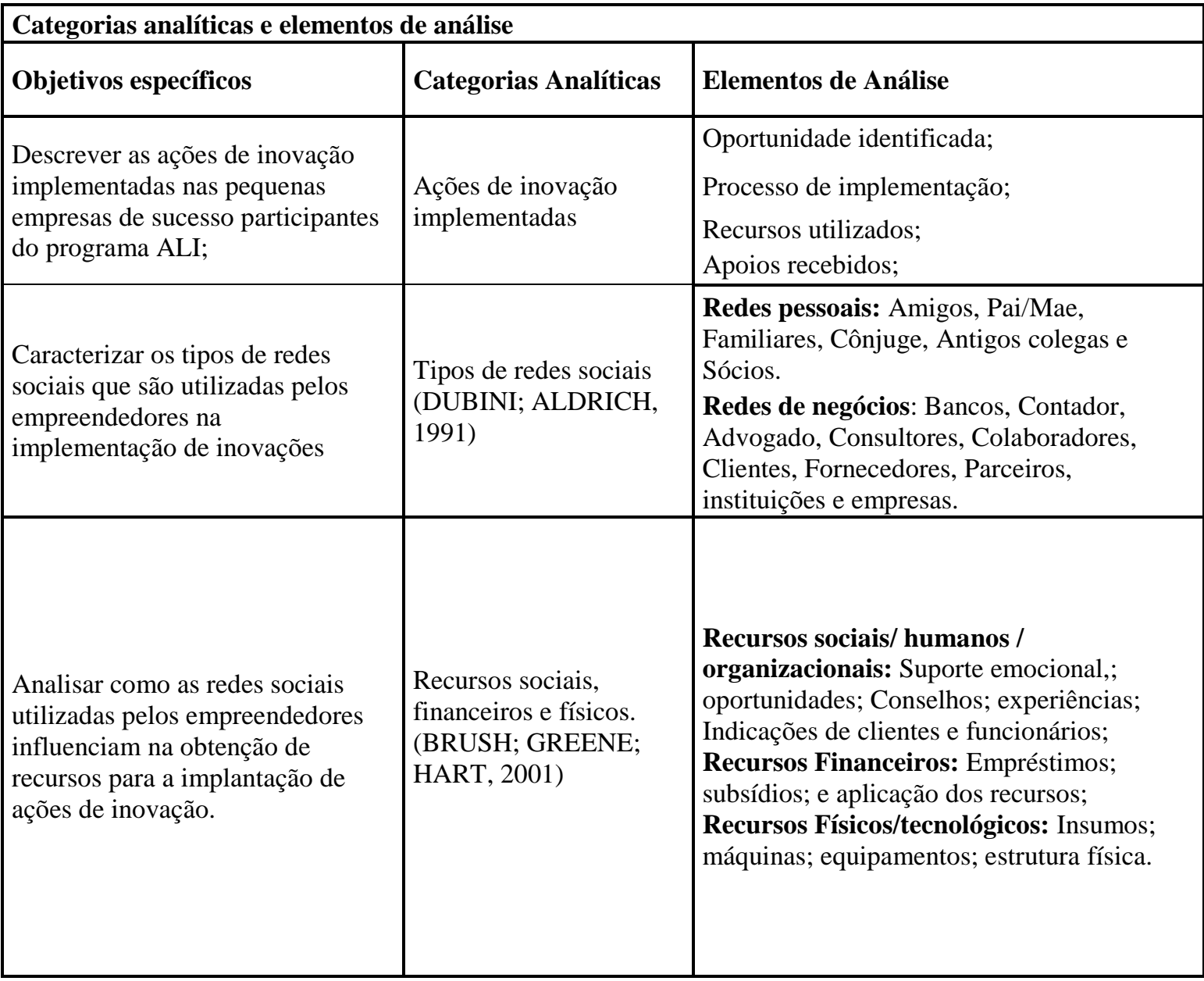

Fonte: Elaborada pelos autores (2017)

\section{Descrição e Análise dos dados}

A descrição e análise dos casos foi realizada levando em consideração as categorias analíticas baseadas nos objetivos do estudo, as semelhanças e diferenças entre os casos e, quando possível, a comparação com os estudos apresentados na fundamentação teórica.

\subsection{Características das empresas e empreendedores}

As empresas do estudo foram analisadas de acordo com os seguintes aspectos: atividade econômica, cadeia produtiva, tempo no mercado, porte da empresa, número de colaboradores, enquadramento societário.

Com relação à atividade econômica, são apresentadas duas empresas de serviços e uma do comércio varejista.

Ambas empresas são organizações familiares de primeira ou segunda geração. Uma delas está seguindo para a terceira geração e a outra. Essas constatações evidenciam a consolidação das empresas, uma vez que, para Stamm e Lubinski (2011) a sucessão para a 
segunda geração nas empresas familiares configura-se como um período crítico para a atividade empresarial. Wright e Kellermanns (2011) definem uma empresa familiar como aquela que tem a intenção transgeracional, ou seja, que é administrada por uma família com a intenção de deixar a empresa para seus descendentes. No que se refere à situação societária das empresas estudadas, observou-se que 2 casos são empresas familiares em diferentes estágios de sucessão.

No quadro 2 é apresentado um resumo das características das empresas:

\section{Quadro 2 - Características das Empresas}

\begin{tabular}{|l|l|l|l|l|l|l|}
\hline & $\begin{array}{l}\text { Atividade } \\
\text { Econômica }\end{array}$ & $\begin{array}{l}\text { Cadeia } \\
\text { Produtiva }\end{array}$ & $\begin{array}{l}\text { Ano de } \\
\text { Fundação }\end{array}$ & $\begin{array}{l}\text { Porte da } \\
\text { Empresa }\end{array}$ & $\begin{array}{l}\text { Pessoas } \\
\text { Ocupadas }\end{array}$ & Situação Societária \\
\hline Caso 1 & Serviços & $\begin{array}{l}\text { Tecnologia da } \\
\text { Informação }\end{array}$ & 2003 & Pequena Empresa & 11 & Empreendedor e filho \\
\hline Caso 2 & Serviços & $\begin{array}{l}\text { Tecnologia da } \\
\text { Informação }\end{array}$ & 2009 & Pequena Empresa & 11 & $\begin{array}{l}\text { Empreendedor e } \\
\text { funcionário sócio } \\
\text { minoritário }\end{array}$ \\
\hline Caso 3 & Comércio & Variedades & 1993 & Pequena Empresa & 31 & Três irmãos sócios \\
\hline
\end{tabular}

Fonte: Elaborada pelos autores (2017)

Já no que se refere ao perfil dos empreendedores, foram considerados os seguintes aspectos: gênero, idade, naturalidade, escolaridade, experiência profissional e tempo de atuação no negócio.

No tocante à escolaridade dos entrevistados, todos possuem formação de nível superior. Para Shook, Priem e McGee (2003) várias características tais como a formação, experiências anteriores e habilidades adquiridas influenciam a criação de oportunidades empreendedoras.

Com relação às experiências profissionais dos empreendedores analisados: no caso 1, o empreendedor possui vasta experiência como bancário, professor universitário e consultor empresarial, o que o ajudou a identificar a oportunidade de negócio e de gerir com sucesso os anos mais complicados. No caso 5, o empreendedor possui experiência anterior como programador de sistemas bancários, o que lhe auxiliou na identificação da oportunidade do negócio. Já o caso 3, se trata de empresas familiares de segunda geração, os empreendedores entrevistados possuem experiência anterior no próprio negócio e aprenderam a trabalhar com seus pais. No quadro 3 a seguir é apresentado um resumo das características dos empreendedores das empresas pesquisadas: 
Quadro 3 - Características dos Empreendedores

\begin{tabular}{|l|l|l|l|l|c|}
\hline & Gênero & Idade & Formação & $\begin{array}{l}\text { Experiências } \\
\text { profissionais }\end{array}$ & Tempo no negócio \\
\hline Caso 1 & Masculino & 61 & Administração & $\begin{array}{l}\text { Bancário, professor } \\
\text { universitário e consultor }\end{array}$ & 13 anos \\
\hline Caso 2 & Masculino & 35 & $\begin{array}{l}\text { Ciência da } \\
\text { Computação }\end{array}$ & $\begin{array}{l}\text { Programador de } \\
\text { Sistemas bancários }\end{array}$ \\
\hline Caso 3 & $\begin{array}{l}\text { Feminino, } \\
\text { Masculino e } \\
\text { Masculino }\end{array}$ & $\begin{array}{l}44,48, \\
51\end{array}$ & $\begin{array}{l}\text { Biologia, } \\
\text { Administração e } \\
\text { Técnico Contábil }\end{array}$ & Empresa Familiar & 20 anos \\
\hline
\end{tabular}

Fonte: Elaborada pelos autores (2017)

\subsection{Inovações em produto ou serviços, redes sociais empreendedoras e recursos acessados}

Embora o termo inovação tenha destaque na literatura sobre $P \& D$ e inovação tecnológica, e geralmente ser associado às grandes empresas (MEISSNER; KOTSEMIR, 2016), para as pequenas empresas a inovação assume um papel estratégico no tocante à competitividade e sua consequente sobrevivência (AZOLAY; SHANE, 2001). Nesse sentido, as tipologias de inovação aplicadas nas pequenas empresas devem ser analisadas tendo em vista as características peculiares das MPEs (MALDONADO; DIAS; VARVAKIS, 2009)

No que se refere ao tipolo da inovação nas empresas pesquisadas, questionou-se aos empreendedores acerca das inovações em produtos/serviços. Verificou-se que as inovações destacadas nos casos estudados envolveram a disponibilização de serviços relativos aos produtos principais, lançamento de novas linhas e aumento do mix de produtos comercializados recorrente da expansão do espaço físico ou dinamização do layout.

Com relação à disponibilização de novos produtos ou serviços, todos os empreendedores implantaram inovações. O empreendedor do caso 1, além de disponibilizar o serviço de sala de videoconferência, também montou um kit consultoria / assessoria em parceria e cooperação com seus próprios clientes, combinando os diversos serviços oferecidos por eles. De forma similar, no caso 2 foram lançados dois novos pacotes que combinam outros serviços específicos para pequenas empresas. Tal inovação pode ser reflexo da aplicação da inovação aberta em pequenas empresas (VRANDE et al, 2009) que define uma série de práticas de exploração de tecnologia e implementação de inovações em cooperação com concorrentes e parceiros e clientes.

Os empreendedores do caso 3 lançaram novas linhas de produtos devido à expansão da estrutura física e capacidade produtiva que possibilitou inaugurar uma sessão infantil na loja. Além disso, em parceria com consultores do SEBRAE, construíram um software online de criação de lista de casamentos. Constatou-se nos casos analisados, que as inovações foram feitas com o uso criativo dos recursos escassos ou externos, sem planejamento estruturado e com a confiança em nas experiências dos empreendedores. Essa forma de inovar foi também apresentado por Berends et al. (2014) que afirma que as pequenas empresas não costumam implantar processos formalizados de inovação de produtos ou serviços.

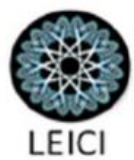


Os empreendedores deste estudo demonstraram que são muitas as dificuldades de inovação de produtos para as pequenas empresas. Dentre outros fatores, destacam como principais dificuldades as questões jurídicas e fiscais, dificuldade com a mão de obra capacitada e a aversão ao risco. Essas dificuldades ae assemelham a algumas encontradas no estudo de Feldens, Maccari e Garcez (2012), que destacou quatro das principais barreiras à inovação em pequenas empresas no Brasil.

Com relação às redes sociais dos empreendedores que adotaram inovações de produto e serviços verificou-se que nas redes pessoais, em geral, por se tratar de empresas familiares, foram os sócios familiares os principais influenciadores, com a disponibilização de recursos sociais e humanos. Para Stamm e Lubinski (2011) essas empresas familiares são diretamente influenciadas pelos familiares de diferentes graus de proximidades.

Observou-se também a importância dos amigos, empreendedores ou não, para a inovação em produtos nas empresas estudadas. Nesse sentido, o estudo de Elfring e Hulsink (2007) reafirma a importância dos laços fortes, como família e amigos nos momentos iniciais da inovação e destaca que são esses laços que reduzem a insegurança do empreendedor com o apoio moral e técnico.

Já nas redes de negócios, foram identificados diversos contatos profissionais que influenciaram diretamente nas inovações em serviços. Os empreendedores das empresas analisadas nesse estudo, são em geral, influenciados pelos clientes para a construção da ideia da inovação e pelos concorrentes, fornecedores e parceiros do mesmo segmento no processo de implementação. Assim o estudo de Depropris (2002) ressaltou a importância do relacionamento com fornecedores para a construção da inovação e, de forma similar, o estudo de Rothaermel e Deeds (2006) destaca que a interação com parceiros e concorrentes do mesmo segmento é um fator importante para a inovação.

Esse resultado corrobora com o modelo conceitual proposto por Huang, Lai e Lo (2012) que buscou investigar o potencial de influência dos laços sociais na inovação de pequenas empresas e se baseia em um construto de três dimensões de redes de relacionamento para a inovação: Interação com fornecedores, clientes e concorrentes.

Com relação aos recursos acessados pelos empreendedores nessas redes de negócios, destacam todos os seis tipos de recursos conceituados por Brush, Greene e Hart (2001) com a predominância dos recursos financeiros na forma de subsídios e financiamentos. Essa realidade corrobora com Le e Nguyen (2009) destaca a importância do relacionamento com bancos para a facilitação da implementação da inovação, uma vez que dificilmente o empreendedor possui recursos próprios para inovar.

Esses resultados encontram respaldo na literatura existente. Diversos autores (HAGE; HOLLINGSWORTH, 2000; PITTAWAY et al., 2004; PARTANEN, CHETTY e RAJALA, 2014; LEENDERS; DOLFSMA, 2016) destacam que a própria dinâmica da pequena empresa substitui a possibilidade de inovações oriundas somente do ambiente interno por inovações pautadas em conhecimentos externos, de relacionamentos com agentes de fora da organização com os de dentro da organização.

Os agentes externos que influenciam as inovações podem vir de qualquer relacionamento que do empreendedor. No quadro 5 a seguir é apresentado um resumo das inovações em produtos/serviços, suas redes sociais e recursos acessados das empresas analisadas:

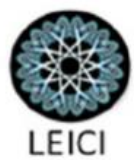


Quadro 4 - Inovações, Redes Sociais e Recursos acessados

\begin{tabular}{|c|c|c|c|}
\hline Casos & $\begin{array}{c}\text { Inovações em } \\
\text { Produtos /Serviços }\end{array}$ & Redes Sociais & Recursos Acessados \\
\hline \multirow{3}{*}{ Caso 1} & \multirow{2}{*}{$\begin{array}{l}\text { Sala } \\
\text { videoconferência }\end{array}$} & $\begin{array}{l}\text { Redes pessoais - Filho e sócio; Antigo } \\
\text { colega de profissão }\end{array}$ & Físicos, Sociais e Humanos \\
\hline & & $\begin{array}{l}\text { Redes de negócios - Bancos; clientes; } \\
\text { concorrentes. }\end{array}$ & $\begin{array}{l}\text { Tecnológicos, Financeiros e } \\
\text { Sociais. }\end{array}$ \\
\hline & Kit Serviços & $\begin{array}{l}\text { Redes de negócios - Clientes e } \\
\text { parceiros; Advogados; Consultores; } \\
\text { Contadores }\end{array}$ & $\begin{array}{l}\text { Sociais, Humanos e } \\
\text { Organizacionais }\end{array}$ \\
\hline \multirow{5}{*}{ Caso 2} & \multirow{2}{*}{ Sistema PagCerto B.I } & $\begin{array}{l}\text { Redes Pessoais - Amigos } \\
\text { empreendedores }\end{array}$ & Sociais \\
\hline & & $\begin{array}{l}\text { Redes de Negócios - Clientes e } \\
\text { Programadores }\end{array}$ & $\begin{array}{l}\text { Sociais, Humanos e } \\
\text { Organizacionais. }\end{array}$ \\
\hline & \multirow{2}{*}{ Sistema de check-out } & $\begin{array}{l}\text { Redes Pessoais - Amigos } \\
\text { empreendedores }\end{array}$ & Sociais e Humanos \\
\hline & & $\begin{array}{l}\text { Redes de Negócios - Clientes e } \\
\text { Programadores }\end{array}$ & $\begin{array}{l}\text { Sociais, Humanos e } \\
\text { Organizacionais. } \\
\end{array}$ \\
\hline & $\begin{array}{l}\text { Completinha da } \\
\text { PagCerto }\end{array}$ & $\begin{array}{l}\text { Redes de Negócios - Clientes, } \\
\text { Programadores, Fornecedores. }\end{array}$ & $\begin{array}{l}\text { Físicos, Sociais, Humanos e } \\
\text { Organizacionais. }\end{array}$ \\
\hline \multirow{4}{*}{ Caso 3} & \multirow{2}{*}{$\begin{array}{l}\text { Inauguração da } \\
\text { sessão infantil }\end{array}$} & $\begin{array}{l}\text { Redes Pessoais - Sócios irmãos e } \\
\text { Antigos colegas professores }\end{array}$ & Sociais \\
\hline & & $\begin{array}{l}\text { Redes de Negócios - Fornecedores e } \\
\text { Colaboradores. }\end{array}$ & $\begin{array}{l}\text { Físicos, Sociais, Humanos e } \\
\text { Organizacionais.. }\end{array}$ \\
\hline & \multirow{2}{*}{$\begin{array}{l}\text { Sistema online de } \\
\text { criação de lista de } \\
\text { casamento }\end{array}$} & Redes Pessoais - Sócios irmãos & Sociais \\
\hline & & $\begin{array}{l}\text { Redes de Negócios - Clientes e } \\
\text { Programadores }\end{array}$ & $\begin{array}{l}\text { Sociais, Humanos e } \\
\text { Organizacionais.. }\end{array}$ \\
\hline
\end{tabular}

Fonte: Elaborada pelos autores (2017)

\section{Considerações Finais}

Percebe-se que as inovações implementadas são semelhantes nas empresas analisadas neste estudo. Uma provável explicação pode ser o fato de todas elas terem participado do Programa ALI e receberem intervenções padronizadas durante o atendimento do agente local de inovação.

Com relação às inovações em produtos, verificou-se que a grande parte delas foi implementada em decorrência da ampliação da estrutura física ou reorganização do layout interno que possibilitou a disponibilização de novas linhas e o atendimento ao um novo segmento.

Verificou-se que os empreendedores recorrem a seus familiares, cônjuges e, em menor grau e aos amigos para auxilio na implementação de inovações. Essa escolha pode ser explicada pela quantidade de empresas familiares presentes nesse estudo, uma vez que, em geral, os parentes que atuam na empresa são as redes pessoais mais relevantes. Já no tocante às redes de negócios, destacou-se a importância do Agente Local de Inovação e dos 
consultores ligados ao SEBRAE, pelo perfil de empresas de sucesso do Programa ALI, que participaram de todas as etapas do programa.

Verificou-se por fim, que essas redes sociais dos empreendedores favoreceram a obtenção dos diferentes tipos de recursos em diferentes situações. Os recursos acessados pelas redes pessoais em geral foram os sociais, com os feedbacks dos familiares, apoio moral e técnico; e recursos humanos, com sugestões, conhecimentos formais ou informais e contatos com outras instituições. De forma mais isolada, foram relatadas o acesso a recursos organizacionais por essas redes, com a disponibilização de ferramentas de gestão, reorganização empresarial e conhecimentos sobre o segmento ou cultura organizacional.

Foi relatada também a influência de contatos como os ALIs, colaboradores, fornecedores, clientes, parceiros, SEBRAE, SENAI, designers, arquitetos, consultores e instrutores. Em todas essas redes de negócios foram utilizados os cinco tipos de recursos: físicos, com a disponibilização de máquinas, equipamentos e insumos; tecnológicos, com licenças de softwares e novas tecnologias aplicadas ao negócio; financeiros, com subsídios e financiamentos; sociais, com sugestões e apoio técnico e moral; humanos, com conhecimento e habilidades específicas; e organizacionais, com a aplicação de ferramentas de gestão, conhecimento sobre o segmento e organizações.

Nas empresas pesquisadas ficou evidente que essas redes sociais influenciam diretamente a implementação de inovações e configuram o suporte emocional, técnico, estratégico e operacional das ações de inovação. O SEBRAE nesse sentido, ao desenvolver o Programa ALI, visando incentivar o desenvolvimento de inovações em empresas de pequeno porte, promove interações com novas redes sociais e fortalece as já existentes.

Ainda assim, é preciso reforçar que as agências de apoio devem destacar a importância às redes sociais empreendedoras para a concretização da inovação, uma vez que a pequena empresa nem sempre conta com os recursos necessários para implementar essas ações. É preciso então que os empreendedores percebam a contribuição de cada relacionamento e esteja atenta a interação com outros empreendedores, agências de fomento à inovação, universidades, conselhos de classes, núcleos de empreendedorismo, entre outras instituições.

Diante do exposto, sugere-se pesquisas futuras a realização de novas pesquisas, envolvendo os temas inovação na pequena empresa e redes sociais empreendedores em uma perspectiva longitudinal do processo de inovação na pequena empresa.

\section{REFERENCIAS}

ALDRICH, H.; ZIMMER, C. Entrepreneurship through social networks. In D. L. SEXTON, D. L.; SMILOR, R. W. (org.), The Art and Science of Entrepreneurship, p. 3-23, 1986.

ALVIM, P. Inovação na pequena empresa: como alavancar. São Paulo, PROTAP 97, 1997.

BAREGHEH, A.; ROWLEY, J.; SAMBROOK, S. Towards a multidisciplinary definition of innovation. Management Decision, v. 47, p. 1323-1339. 2009.

BAUMOL, W. J. The Free-Market Innovation Machine: Analyzing the Growth Miracle of Capitalism. Princeton, N. J.: Princeton University Press. 2002. 
BERENDS, H., JELINEK, M., REYMEN, I.; STULTIËNS, R. Product Innovation Processes in Small Firms: Combining entrepreneurial effectuation and managerial causation. Journal of Product Innovation Management, v. 31, n. 3, 616-635. 2014

BIRLEY, S. The role of networks in the entrepreneurial process. Journal of Business Venturing, v.1., n.1, p. 107-117, 1985.

BORGES, M.; AFUAH, A.; BASTIAN, B. Users as innovators: A review and future research directions. Journal of Management, v. 36, n. 4, p. 857-875, 2010.

BOTELHO,M. R. A; CARRIJO, M. C; KAMASAKI, G. Y. Inovações, pequenas empresas e interações com instituições de ensino/pesquisa em arranjos produtivos locais de setores de tecnologia avançada. Revista Brasileira de Inovação. v. 2, n. 3, p. 205 - 229, 2007.

BRUSH, C. GREENE, P.; HART, P. From initial idea to unique advantage: the entrepreneurial challenge of constructing a resource base. Academy of Management Executive, v. 15, n.1, p.64-80, 2001.

CAMPOS, L. B. P.; CAMPOS, R. J. Análise multi-casos da gestão da inovação em empresas de pequeno porte. Pretexto. v. 14, n. 1 p. 36-51. 2013

CARVALHO, G. D. G.; SILVA, W. V.; PÓVOA, A. C. S.; CARVALHO, H. G. Radar da Inovação como Ferramenta para o Alcance de Vantagem Competitiva para Micro e Pequenas Empresas. Revista de Administração e Inovação, v. 12, n. 4, p. 162-186, 2015.

DEPROPRIS, L. Types of innovation and inter-firm co-operation. Entrepreneurship and Regional Development, v. 14, p. 337-353. 2002

DRUCKER, P. Inovação e espírito empreendedor: prática e princípios. São Paulo: Pioneira Thomson, 2002.

DUBINI, P.; ALDRICH, H. Personal and extended networks are central to the entrepreneurial process. Journal of Business Venturing, v. 6, p. 305-313. 1991

ELFRING, T., HULSINK, W. Networking by entrepreneurs: patterns of tie formation in emerging organizations. Organization Studies v. 28 n. 12, p. 1849-1872. 2007

EISENHARDT, K. M. Building theories from case study research. Academy of Management Review, v. 14, n. 4, p. 532-550, 1989.

FELDENS, M. A. ; MACCARI, E. A. ; GARCEZ, M. P. . Barreiras para a inovação em produtos nas pequenas e médias empresas de tecnologia no Brasil. BBR. Brazilian Business Review , v. 9,n. 3, p. 1-24, 2012.

FLIGSTEIN, N., DAUTER, L. A sociologia dos mercados. Caderno CRH, vol.25, n.66, 2012.

FREEMAN, C.; SOETE, L. Developing science, technology and innovation indicators: What we can learn from the past. Research policy, v. 38, n. 4, p. 583-589, 2009.

GRANOVETTER, M. S. The strength of weak ties. a network theory revisited. Sociological Theory, v. 1, p. 201-233, 1983. 
GRANOVETTER, M. Ação econômica e estrutura social: o problema da imersão. Revista Administração Eletrônica, n. 6 v. 1, 2007.

HUANG, H. C.; LAI, M. C.; LO, K. W. Do founders' own resources matter? The influence of business networks on start-up innovation and performance. Technovation. v. 32, p. 316-327. 2012

HAGE, J.; HOLLINGSWORTH, J. R. A strategy for analysis of idea innovation networks and institutions', Organization Studies v. 21, 2000.

HUGGINS, R. Forms of network resource: Knowledge access and the role of inter-firm networks. International Journal of Management Reviews, v. 12, n. 3, p. 335-352. 2010

HUGGINS, R.; THOMPSON, P. Entrepreneurship, innovation and regional growth: a network theory. Small Business Economics, v. 45, n. 1, p. 103-128. 2015

JENSEN, K. W.; SCHOTT, T. Start-up firms' networks for innovation and export: facilitated and constrained by entrepreneurs' networking in private and public spheres. Soc. Netw. Anal. Min. v. 48, n 5 p.48-60, 2014

JULIEN, P-A. Empreendedorismo regional e economia do conhecimento. São Paulo: Saraiva. 2010.

LE, N.T.B.; NGUYEN, T.V. The impact of networking on bank financing: The case of small and medium-sized enterprises in Vietnam. Entrepreneurship Theory and Practice, v. 33, p. 867-887. 2009

LEENDERS, R. T. A. J.; DOLFSMA, W. A. Social Networks for Innovation and New Product Development. Journal of Product Innovation Management. v. 33, n. 2, p. 123-131. 2016

MALDONADO, M.; DIAS, N.; VARVAKIS, G. Managing innovation in small hightechnology firms: a case study in Brazil. Journal of technology management \& innovation, v. 4, n. 2, p. 130-142, 2009

MELLO, C. M. ; MACHADO, H. V. ; JESUS, M. J. Considerações sobre a inovação em PMES: o papel das redes e do empreendedor. Revista de Administração da UFSM, v. 3, p. 41- 57. 2010

MEISSNER, D.; KOTSEMIR, M.; N. Conceptualizing the Innovation Process Towards the 'Active Innovation Paradigm' - Trends and Outlook. Journal of Innovation and Entrepreneurship, v.5, n. 14. 2016

NEUMAN, L. W. Social research methods: qualitative and quantitative approaches. Boston: Allyn \& Bacon, 1997.

NEWBERT, N., L.; TORNIKOSKI, E. T.; QUIGLEY, N. R. Exploring the evolution of supporter networks in the creation of new organizations. Journal of Business Venturing, v. 28, p. 281-298. 2013 
OCDE. Manual de Oslo: Proposta de Diretrizes para Coleta e Interpretação de Dados sobre Inovação Tecnológica. Tradução Financiadora de Estudos e Projetos. Brasília: Finep, tradução português, 2005.

OSTGAARD, T., A., BIRLEY, S. Personal networks and firm competitive strategy-a strategic or coincidental match? Journal of Business Venturing, v. 9, p. 281-305. 1996.

PAREDES, B. J. B.; SANTANA, G. A. ; CUNHA, T. N. ; AQUINO, J. T. . Uma análise intrassetorial e intersetorial do grau de inovação de empresas de pequeno porte do estado de Pernambuco. RAI : Revista de Administração e Inovação, v. 12, p. 140-161, 2015.

PARTANEN, J.; CHETTY, S. K.; RAJALA, A. Innovation Types and Network Relationships. Entrepreneurship Theory And Practice v. 38, n. 5, p. 1027-1055, 2014

PITTAWAY, L., ROBERTSON, M., MUNIR, K., DENYER, D.; NEELY, A. Networking and innovation: A systemic review of the evidence. International Journal of Management Reviews, v. 5, n. 6, p. 137-168. 2004

RAMANI, S. V.; MUKHERJEE, V. Can breakthrough innovations serve the poor (bop) and create reputational (CSR) value? Indian case studies. Technovation, v. 35, n. 5-6, p. 295$305,2014$.

RESENDE JUNIOR, P. C.; GUIMARÃES, T. A. Inovação em Serviços: o estado da arte e uma proposta de agenda de pesquisa. Revista Brasileira de Gestão de Negócios, v. 14, n. 44, p. 293-313, 2012

ROTHAERMEL, F.T.; DEEDS, D.L. Alliance type, alliance experience and alliance management capability in high-technology firms. Journal of Business Venturing, v. 21, p. 429-460. 2006

SAUNDERS, M.; LEWIS, P.; THORNHILL, A. Research methods for business students. 5 ed., London: Pearson Education Limited, 2009.

SCHOTT, T.; SEDAGHAT, M. Innovation embedded in entrepreneurs' networks and national educational systems. Small Business Economics. v. 43, n. 2, p. 463-476. 2014

SERVIÇO BRASILEIRO DE APOIO ÀS MICRO E PEQUENAS EMPRESAS - SEBRAE. Anuário do trabalho na micro e pequena empresa. 6. ed., Brasília: DIEESE, 2014.

SCHUMPETER, J.A. Teoria do Desenvolvimento Econômico. Editora Fundo de Cultura, Rio de Janeiro, 1998.

SILVA NETO, A. T.; TEIXEIRA, R. M . Mensuração do grau de inovação de micro e pequenas empresas: estudo em empresas da cadeia têxtil confecção em sergipe. Revista de Administração e Inovação, v. 8, n. 3, p. 205 - 229, 2011.

SHOOK, C.; PRIEM, R. L.; MCGEE, J. E. Venture creation and the enterprising individual: a review and synthesis. Journal of Management, v. 29, n. 3, p. 379-399, 2003.

STAMM, I.; LUBINSKI, C. Crossroads of family business research and firm demography: A critical assessment of family business survival rates. Journal of Family Business Strategy, n.2, p. 117-127. 2011. 
TAVARES, B.; FERREIRA, M. A. M.; LIMA, A. T. F. C. Identificação e agrupamento de fatores de relevância na investigação das práticas de gestão das micro e pequenas empresas. Revista de Negócios, v. 14, n. 4, p. 11 - 27, 2009.

TIDD, J; BRESSANT, J; PAVITT, K. Gestão da Inovação. Porto Alegre: Bookman. 2008. TORRÈS, O.; JULIEN, P. A. Specificity and Denaturing of Small Business. International Small Business Journal, v. 23, n. 4, p. 355-377, 2005.

UKKO, J; SAUNILA, M. Facilitating innovation capability through performance measurement: A study of Finnish SMEs. Management Research Review, v. 36, n. 10, p. 991-1010. 2013

VALLE, G. M. V. Empreendedor: Origens, Concepções Teóricas, Dispersão e Integração Revista de Administração Contemporânea, Rio de Janeiro, v. 18, n. 6, pp. 874-891, Nov./Dez. 2014

VALLE, G. M. V.; Fatores Condicionantes do Empreendedorismo: Redes Sociais ou Classes Sociais?. Organização e Sociedade - Salvador, v. 22 - n. 75, p. 583-602 - Out./Dez. - 2015

VRANDE, V; JONG, J. P. J; VANHAVERBEKE, W. ROCHEMONT, M. Open innovation in SMEs: Trends, motives and management challenges. Technovation. v 29. P. 423-437. 2009.

WRIGHT A., M.; KELLERMANNS, F. W. Family firms: A research agenda and publication guide. Journal of Family Business Strategy, n. 2, p. 187-198. 2011.

YIN, R. K. Estudo de caso: planejamento e método. 5 ed., Porto Alegre: Bookman, 2001. 